\section{Time-resolved Fluorescence Immunoassay}

W. Stöcker und C. Krüger

Euroimmun Medizinische Labordiagnostika AG, Lübeck, Deutschland

Synonym(e) DELFIA; TR-FIA; Zeitaufgelöste Fluoreszenz

Englischer Begriff time-resolved fluorescence immunoassay (TR-FIA); delayed emission lanthanide fluorescent immunoassay (DELFIA)

Definition Der Time-Resolved Fluorescence Immunoassay (TR-FIA) ist ein $>$ Sandwich-Assay, bei dem die für die Markierung ( $\triangleright$ Fluoreszenzmarkierung) verwendeten Fluorophore das Emissionslicht zeitversetzt abgeben und das Messsignal zur Reduktion von Störsignalen nach impulsartiger Anregung nur während der Emissionsphase erfasst wird.

Physikalisch - chemisches Prinzip Beim TR-FIA werden als Fluorophore z. B. Chelate aus Diketonen und den Lanthaniden Europium und Terbium verwendet. Bei der impulsartigen Anregung des Metallchelates absorbiert das Diketon die Anregungsenergie und gibt sie an das Lanthanid weiter, das dann, bedingt durch den Umweg zeitversetzt, ein Lichtquant niedrigerer Energie abstrahlt. Auch die fotometrische Erfassung des emittierten Fluoreszenzlichtes erfolgt zeitversetzt. Dadurch werden im Vergleich zu den üblichen Fluoreszenzimmuntests Untergrundfluoreszenz und Streulicht reduziert, da sich diese Störeinflüsse normalerweise nur unmittelbar nach der Anregung bemerkbar machen: Die Lanthanid-Chelate haben Fluoreszenzabklingzeiten von $10-1000 \mathrm{~ms}$, man misst die
Lanthanid-Fluoreszenz nachdem Störungen durch gestreutes Anregungslicht und die kurzlebigen Fluoreszenzen (1-20 ns) der biologischen Proben abgeklungen sind (s. a. $>$ Fluoreszenz, zeitaufgelöste).

Weitere messtechnisch günstige Eigenschaften der Lanthanid-Chelate sind die sehr starke Stokes-Verschiebung von etwa $340 \mathrm{~nm}$ nach $613 \mathrm{~nm}$ und die sehr schmale Emissionsbande mit einer Halbintensitätsbreite von etwa $10 \mathrm{~nm}$. Die Bestimmung wird dadurch zusätzlich empfindlich und reproduzierbar, die Messung beeinflusst biologische Eigenschaften wenig. Der TR-FIA wird meist als Sandwich-Assay mit zwei Antikörpern durchgeführt.

Einsatzgebiet Antigenbestimmungen.

Untersuchungsmaterial Serum, Plasma.

Sensitivität Die analytische Sensitivität der TR-FIA liegt bei $10^{-18}-10^{-20} \mathrm{~mol} / \mathrm{L}$.

Praktikabilität - Automatisierung - Kosten Der TR-FIA weist gleich hohe Empfindlichkeit, Reproduzierbarkeit und Genauigkeit wie der $>$ Radioimmunoassay auf und wäre im Prinzip hinsichtlich Geschwindigkeit der Testdurchführung und breiter Anwendbarkeit dem > Enzymimmunoassay ebenbürtig. Einige TR-FIA sind als manuelle sowie automatisierte Immunoassays verfügbar.

\section{Literatur}

Wild D (2001) The immunoassay handbook. Nature Publishing Group, New York, S 167-168 